\title{
Characterization of Clay/Chitosan Nanocomposites and their Use for Adsorption On Mn(II) from Aqueous Solution
}

\author{
F. H. Abd El-Kader Department \\ Of Physics, Faculty of Science, \\ Cairo University, Giza \\ Egypt
}

\author{
A. M. Shehap \\ Department of Physics, Faculty \\ of Science, Cairo University, \\ Giza, Egypt
}

\author{
A.A. Bakr \\ Egyptian Petroleum \\ Research Institute \\ (Epri), Nasr City, \\ Cairo, Egypt
}

\author{
Omar T. Hussein \\ Department Of Physics, \\ Faculty of Science, Cairo \\ University, Giza, Egypt
}

\begin{abstract}
In this study, composites films were prepared from Chitosan biopolymer and Montmorillonite nanoclay (MMT) by dispersion of MMT into Chitosan solution with different weight percentage $(2.5,5,7.5,10,12.5,15$ and $75 \%$ wt. /wt. nanoclay/chitosan), using both sonication and casting technique methods to obtain good dispersion of nanoclay. The structural properties of these nanocomposites samples examined by XRD and FTIR. The XRD patterns indicating that formation of an intercalated nanostructure as exfoliated and flocculated structure. Also the complexion of the dopant with the biopolymer was examined by FTIR studies. The experiments of Mn(II) ions adsorption were carried out on MMT/chitosan nanocomposites. The effect of various parameters such as $\mathrm{pH}$, contact time, adsorption mass, initial $\mathrm{Mn}$ (II) concentration and temperature on the adsorption of $\mathrm{Mn}$ (II) removal onto MMT/chitosan nanocomposites was investigated. Two adsorption isotherm models were applied Freundlich and Langmuir to fit the experimental data. Langmuir isotherm modeling was suitable for description the data at equilibrium state. The kinetic isotherm was found to follow the pseudo-second-order model. Also, the thermodynamics parameters of the adsorption such as Gibbs free energy $\Delta G^{o}$, entropy $\Delta S^{o}$ and enthalpy $\Delta H^{o}$ were discussed and the results demonstrate that the adsorption process is spontaneous and endothermic.
\end{abstract}

Keywords: MMT/Chitosan; nanocomposites; XRD; IR; adsorption

\section{INTRODUCTION}

Recently, polymer/clay nanocomposites have attracted considerable interest because they combine the structure, physical and chemical properties of inorganic and organic materials. Most work with clay/polymer nanocomposites has concentrated on synthetic polymers, including thermosets such as epoxy polymers, and thermoplastics, such as polyethylene, polypropylene, nylon and poly (ethylene terephthalate) ${ }^{[1]}$. However, the opportunity to combine at nanometric level clays and natural polymers (biopolymers), such as chitosan, appears as an attractive way to modify some of the properties of this polysaccharide including its mechanical and thermal behavior, solubility and swelling properties, antimicrobial activity, bioadhesion, etc. [2].

Clay/Chitosan nanocomposites are economically interesting because they are easy to prepare and involve inexpensive chemical reagents. Chitosan, obtained from chitin, is a relatively inexpensive material because chitin is the second most abundant polymer in nature, next to cellulose ${ }^{[3]}$. In the same way, clays are abundant and low-cost natural materials. In addition, the successful preparation of the nanocomposites still encounters problems, mainly related to the proper dispersion of nano-fillers within the polymer matrix.

The degree of acetylation (DA) and the crystallinity of chitin molecules affect the solubility in common solvents. Reducing the acetylation level in Chitosan ensures the presence of free amino groups, which can be easily protonated in an acid environment, making Chitosan water soluble below $\mathrm{pH}$ about $6.5^{[4,5]}$. In acid conditions, when the amino groups are protonated Fig. (1), chitosan becomes a soluble polycation [6]. The presence of amino groups makes chitosan a cationic polyelectrolyte.

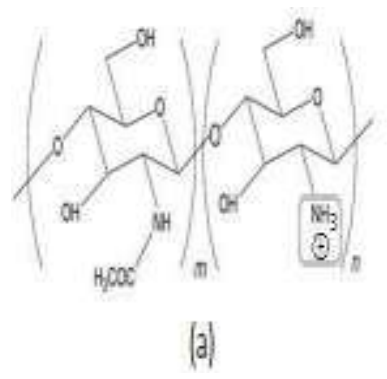

Fig. 1: Schematic illustration of chitosan: (a) at low $\mathrm{pH}$ (less than about 6.5), chitosan's amine groups become protonated (polycation); (b) at higher $\mathrm{pH}$ (above about 6.5), chitosan's amine groups are deprotonated and reactive. 
Clays are classified on the basis of their crystal structure and the amount of the distributed electric charge and their location (deficit or excess) per unit cell. Crystalline clays range from kaolins, which are relatively uniform in chemical composition, to smectites, which vary in their composition, cation exchange properties, and ability to expand. The most commonly employed smectite clay for the preparation of polymeric nanocomposites is bentonite, whose main mineral component is Montmorillonite (MMT) [7]. Montmorillonite (MMT) is a 2:1 layered hydrated aluminosilicate, with a triple-sheet sandwich structure consisting of a central, hydrous alumina octahedral sheet, bonded to two silica tetrahedral sheets by shared oxygen ions as in Fig (2). Isomorphic substitution of $\mathrm{Al}^{+3}$ in the octahedral sheets by $\mathrm{Mg}^{+2}$ (less commonly $\mathrm{Fe}^{+3}, \mathrm{Mn}^{+2}$, and other) and, less frequently, of $\mathrm{Si}^{+4}$ by $\mathrm{Al}^{+3}$ in the tetrahedral sheet, results in a net negative charge on the crystalline layer, which is compensated by the presence of cations, such as $\mathrm{Na}^{+}, \mathrm{K}^{+}$, $\mathrm{Ca}^{+2}$, or $\mathrm{Mg}^{+2}$, sorbet between the layers and surrounding the edges. An idealized MMT has 0.67 units of negative charge per unit cell, in other words, it behaves as a weak acid. These loosely held cations do not belong to the crystal structure and can be readily exchanged by other cations, organic or inorganic
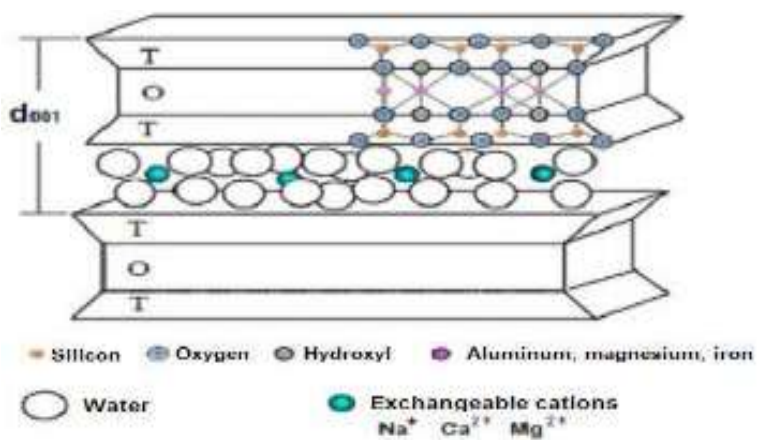

Fig. 2: Schematic of a Montmorillonite, layered clay mineral with a triple-sheet sandwich structure consisting of a central, hydrous alumina octahedral sheet $(\mathrm{O})$, bonded to two silica tetrahedral sheets $(\mathrm{T})$ by shared oxygen's

The system of the Chitosan as a matrix for the nanoclay (MMT) promising as enhancement adsorptive removal of heavy metal ions, quite efficient and fast adsorption, since, it is a perfect nano adsorbents because it has high specific area and there is not any internal diffusion resistance, so after studying the physical properties of this system, we looked for using this system in adsorption process for heavy metal ions such as Manganese (II).

Our target of these paper was the preparation of the biopolymer Chitosan as a matrix of nanoparticles MMT with different percentage ratios of the nanoclay to obtain new composites of specific physical property, as well as , using this system for adsorption the heavy metal ions under equilibrium isotherm modeling and obtaining it's thermodynamics characteristics.

\section{MATERIALS AND METHODS}

\subsection{Material}

Commercially available chitosan powder (Sigma Aldrich) was used. According to the producer data, its deacetylation degree DD was about $80 \%$. Structural formula of Chitosan is presented in fig. (1), commercially available MMT (Sigma Aldrich) with average particle size $10-30 \mathrm{~nm}$ was used as a nano-filler.

Manganese chloride with purity of $99.9 \%(\mathrm{MnCl} 2.4 \mathrm{H} 2 \mathrm{O})$ was purchased from Loba Chemie. Co.

\subsection{Film preparation}

Pure Chitosan film: The appropriate weight of biopolymer Chitosan (1gm) was dissolved in $100 \mathrm{ml}$ of DI water and $2 \%$ acidic acid. The mixture was magnetically stirred continuously and heat $\left(80 \mathrm{C}^{\circ}\right)$ for 4 hours, until the solution mixture becomes a homogenous viscous solution. The solution is poured into Petri dish and left for 3 days to solidify at room temperature. The thickness of the final film was bout $(50 \mu \mathrm{m})$.

Clay/Chitosan nanocomposites: Different weights percentage of Clay nanoparticles were added to water and magnetically stirred vigorously for 3 hours and sonicated (by using 450 sonifier) for 1 hour to prevent the nanoparticles agglomeration. Each weight percentage of sonicated nanoclay was added to Chitosan viscous solution of the corresponding weight and magnetically stirred for 2 hours then sonicated again for 1 hour to get good dispersion without agglomeration as possible. The final nanoclay/chitosan mixture was cast in glass Petri dish; air bubbles were removed by shaking and blowing air and were left until dry. This procedure was repeated to make $(2.5 \%$, $5 \%, 7.5,10 \%, 12.5 \%$ and $15 \%$ Nanoclay/Chitosan composites). The films were about $50 \mu \mathrm{m}$ in thickness. The thicknesses of films were controlled by using the same amount of total materials and the same glass Petri dish size. It is important to mention that we prepared the nanocomposites sample of highly ratio of the nanoclay with chitosan to obtain the optimum composite film to achieve maximum adsorption of manganese (II) as heavy metal ions, as well be seen in the discussion of the adsorption process nextly.

\subsection{Characterization of the composites film}

X-ray diffraction patterns were obtained using advanced refraction system XRD Scintag Ins., USA. The tube used was Copper radiation and the filter was Nickel. The range of $\mathrm{x}$-ray spectra of $2 \Theta$ was over the range $5--70^{\circ}$.

The infrared spectral analysis (IR) of the samples was carried out using PYE Unican spectrophotometer over the range $500-4000 \mathrm{~cm}^{-1}$.

\subsection{Adsorption method}

The manganese $\mathrm{Mn}(\mathrm{II})$ stock solution concentration of 150 $\mathrm{mg} / \mathrm{L}$ was prepared by dissolving Manganese chloride ( $\mathrm{MnCl} 2.4 \mathrm{H} 2 \mathrm{O}$, Loba chemie) in distilled water. The working $\mathrm{Mn}$ (II) solution concentration ranging from 20 to $80 \mathrm{mg} / \mathrm{L}$ for all experiments was freshly prepared from the stock solution. Standard acid $\left(0.01 \mathrm{M} \mathrm{HNO}_{3}\right)$ and base solutions $(0.125 \mathrm{M} \mathrm{NaOH})$ were used for $\mathrm{pH}$ adjustments at $\mathrm{pH} 3,4,4.5,5,5.5,6,7,8$ and 9. The $\mathrm{pH}$ of the solution was measured with a $\mathrm{pH}$ meter (Thermo Orion $5 \mathrm{Star}$ ) 
The experiments for removal of manganese ions from dilute aqueous solutions by the addition of adsorbent (chitosan/clay) masses $0.10,0.15,0.20,0.25,0.30,0.35$ and $0.40 \mathrm{~g} / \mathrm{L}$ were carried out at different temperatures $(298,308$ and $318 \mathrm{k}$ ). After continuous stirring over a magnetic stirrer at about $160 \mathrm{rpm}$ for a predetermined time intervals $(15,30$, $45,60,75,90$ and $105 \mathrm{~min}$ ), the solid and solution were separated by centrifugation at $3000 \mathrm{rpm}$ for $15 \mathrm{~min}$ and slightly dried at ambient temperature. $\mathrm{Mn}$ (II) concentration was determined by Spectro-photometer, LaMotte, model SMART Spectro, USA and the solid phase was analyzed. The contact time, allows the dispersion of adsorbent and metal ions to reach equilibrium conditions, as found during preliminary experiments.

\section{RESULT AND DISCUSSION}

\subsection{X-ray diffraction (XRD)}

$\mathrm{X}$-Ray diffraction is an advanced technique to understand the Skelton structure in semicrystalline polymers or clay minerals and these composites (organoclay). The XRD analysis was used to study the crystalinity and the structural change of the prepared samples as in fig. (3-1a) of the pure chitosan that indicates the peaks at around $2 \Theta \approx 10^{\circ}, 20^{\circ}$ and $23^{\circ}$ confirm the semicrystalline nature of Chitosan. This result is consistent with that found in previous literature ${ }^{[8,9]}$. The peaks over the range from $10^{\circ}$ to $20^{\circ}$ for Chitosan films showed that it could exist in two distinct crystal form I and II. This morphological structure varing from spherical to roods depending on the film processing condition. It is worthy to mention that the molecules does not affect the crystal form but does affect the crystallite size and morphological character (rod or spherulite) of the cast film. Also different solvent treatment enhance spherulite structure . The evaluation of form I related to crystal form of $\mathrm{a}=7.76$ $\mathrm{A}^{\mathrm{o}}, \mathrm{b}=10.19 \mathrm{~A}^{\mathrm{o}}, \mathrm{c}=10.3 \mathrm{~A}^{\mathrm{o}}$ and $\beta=90^{\circ}$ i.e. it is orthorhombic unit cell with two monomer units per epeat along the chain axis while form II related to crystal of a $=4.4 \mathrm{~A}^{\mathrm{o}}, \mathrm{b}=10 \mathrm{~A}^{\mathrm{o}}, \mathrm{c}=10.3 \mathrm{~A}^{\mathrm{o}}$ and $\beta=90^{\circ}[8]$. Fig. (3-1b) shows typically XRD of MMT that characterized by peak at $2 \Theta=8,19.8,20.8,26.5$, and $45.5^{\circ}$ of highest relative intensity respectively nano clay as found previously ${ }^{[10]}$. Many numbers of researchers were interesting to study the XRD of the clay at specific peak at $2 \Theta$ around $7^{\circ}$ corresponding to a basal spacing d001 ranging from

12 $-14 \mathrm{~A}^{\mathrm{o}}$

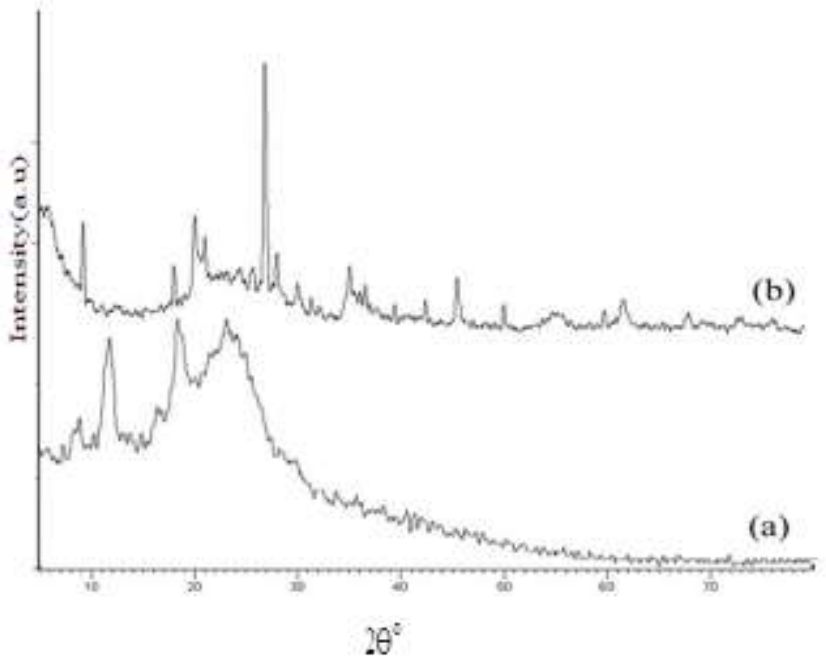

Fig. 3-1: X-ray diffraction pattern of (a) Pure Chitosan (b) Pure MMT.

The nanoclay dispersion within chitosan at different level of weight percentage for the composite samples has been characterized by XRD as in fig. (3-2). The XRD ranging up to $2 \Theta \approx 10$ to $25^{\circ}$ sharing for both chitosan and nanoclay is quite different than that observed for XRD of the both two starting materials indicating the occurred complexation between chitosan and the nanoclay. This gives an evidence reason for taking inconsideration the changes occurred for the typical diffraction peak bellowing to MMT around $2 \Theta$ $\approx 7^{\circ}$ to look for the structural changes occurred in the composites of the different levels of weight ratio ${ }^{[11]}$.

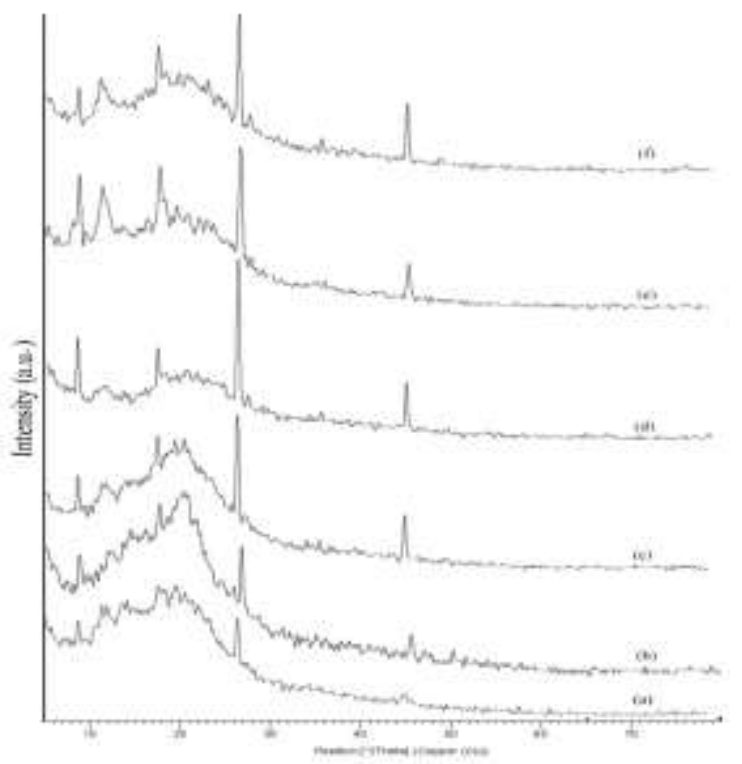

Fig. 3-2: X-ray diffraction patterns of (a) $2.5 \%$ (b) $5 \%$ (c) $7.5 \%$ (d) $10 \%$ (e) $12.5 \%$ (f) $15 \%$. 
Is well known that there are three types of the polymers layer silicate interaction possible to be occurred according to the relative distribution dispersion of the stacks of nanoclay particles in the biopolymers dissolved in water with acidic media ${ }^{[12,13]}$.

\section{a. Phase separated structure :}

When the organic polymer is interact with the inorganic clay and the polymer is unable to intercalate within the clay layers and the clay is dispersed as aggregate or particles with layers stacked together within the polymer matrix. The obtained composite structure is considered as phase separated.

\section{b. Intercalated structure :}

When one or more polymer chain are inserted into the interlayer space and cause to the increasing of the interlayer spacing, but the periodic array of the clay is still exist, the intercalated nanocomposites is formed. The presence of polymers chain in the galleries cause to the decreasing of the electrostatic force between the layers but is not totally dissolved. A well - ordered multilayers morphology built up with high interference interactions consisted of polymer chain and clay layer.

\section{c. Exfoliated (Delaminated) structure :}

This structure is obtained as the insertion of polymer chain into the clay galleries causes the separation of the layers one another and individual layers are dispersed within the polymer matrix. The exfoliated structure is occurred when the increasing of the inter layer spacing become more than 8 $-10 \mathrm{~nm}$. Due to the well dispersion of the individual clay layer, high aspect ratio is obtained and lower clay content is needed for exfoliated nanocomposites. At that state a most significant improvement in polymers properties is obtained due to the large surface interaction between polymer and nanoclay.

Chitosan has good miscibility with the nanoclay (MMT) due to its hydrophilic and poly cationic properties in acidic media and can easily intercalate into the interlayers by means of cationic exchange. In our case, the specific reflection peak of $\mathrm{d}_{001}$ is detected at $2 \Theta=8^{\circ}$ and the movement of the basal $\mathrm{d}_{001}$ of MMT were to higher angle because the prepared composite samples were in direction of increasing the percentage ratio of the nanoclay. The proper of the three types of interaction are available according to the ratio of the nanoclay and the chitosan.

The movement of the specific diffraction peak of MMT indicates formation of the flocculated-intercalated structure in the composites of the different percentage of the nanoclaybiopolymers under studying. This structure is due to the hydroxylated edge-edge interaction of the silicate layers ${ }^{[14]}$, in addition to the electrostatic interaction of the amino groups in chitosan to adhere the negatively charge surface of the inter layers in nanoclay. Also the change of the intensity of the XRD confirms the new structural of the composite samples. Finally from fig. (3-3), it is possible to expect the formation of an intercalated nanostructure as exfoliated and flocculated structure ${ }^{[12,13]}$.

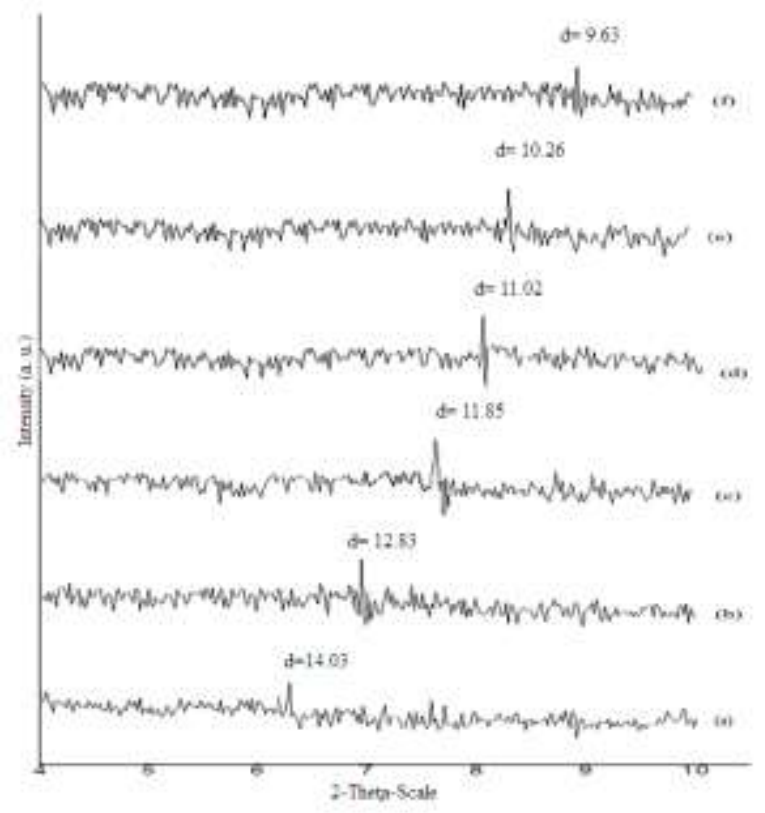

Fig. 3-3: The movement of the d-spacing for do01 of the (a) $2.5 \%$, (b) $5 \%$, (c) $7.5 \%$, (d) $10 \%$, (e) $12.5 \%$, and (f) $15 \%$ nanoclay/chitosan composite films.

\subsection{FTIR spectroscopy}

Infrared absorption spectroscopy can be employed in quantitative analysis and structure determination of the compounds. Fig. (4) depicts characteristic bonds of the pure Chitosan as recorded. The main absorption bands at 3750 to $3000 \mathrm{~cm}^{-1}$ are due to the stretching vibration of $\mathrm{O}-\mathrm{H}$ groups that overlapped to the stretching vibration of $\mathrm{N}-\mathrm{H}$ band while the two absorption stretching band of $\mathrm{C}-\mathrm{H}$ band in $\mathrm{C}-\mathrm{H}_{2}$ appear at $v_{1}=2921 \mathrm{~cm}^{-1}$ and in $\mathrm{CH}_{3}$ at $v_{2}=2875 \mathrm{~cm}^{-1}$ respectively. The bending vibration of methylene and methyl groups were also visible at $v=1377$ and $v=1429$ $\mathrm{cm}^{-1}[14]$. It is well known for Chitosan that the absorption range from 1680 to $1480 \mathrm{~cm}^{-1}$ was related to the vibration of the carbonyl bands $\mathrm{C}=\mathrm{O}$ of the amide group CONHR as characteristic absorption bands ${ }^{[15]}$. It is worth to mention that the vibration of the amine group $\mathrm{NH}_{2}$ is observed at $\approx 1580 \mathrm{~cm}^{-1}$.

The amide I group is observed at $v_{1}=1646 \mathrm{~cm}^{-1}$ while the vibration $\mathrm{C}=\mathrm{O}$ of the protonated amine group $\left(\mathrm{NH}_{3}\right)$ is visible at $\mathrm{v}_{2}=1540 \mathrm{~cm}^{-1}$ that presented the amide II. The characteristic band of amide III is observed at $1255 \mathrm{~cm}^{-1}$. The amide I and amide II absorption bands suggest that Chitosan is a partially deacetylated product ${ }^{[16]}$. It is well known that the reducing of the acetylation level in Chitosan ensure the presence of the free amino groups which can be easily protonated in an acid environment making Chitosan water soluble. The presence of the amino groups makes Chitosan a cationic polyelectrolyte. Also the absorption in the range of $1160 \mathrm{~cm}^{-1}$ to $1000 \mathrm{~cm}^{-1}$ has been attributed to vibrations of the CO group ${ }^{[16]}$. The band at $v=1153 \mathrm{~cm}^{-1}$ is due to $\mathrm{C}-\mathrm{O}$ asymmetric vibration in the oxygen bridge 
resulting from deacetylation of chitosan. The bands near 1080 to 1021 are attributed to $v_{\text {co }}$ of the ring $\mathrm{COH}, \mathrm{COC}$ and $\mathrm{CH}_{2} \mathrm{OH}$. The small peak at $894 \mathrm{~cm}^{-1}$ is corresponding to the wagging $(\mathrm{C}-\mathrm{H})$ of the saccharide structure of Chitosan $[17,18$,

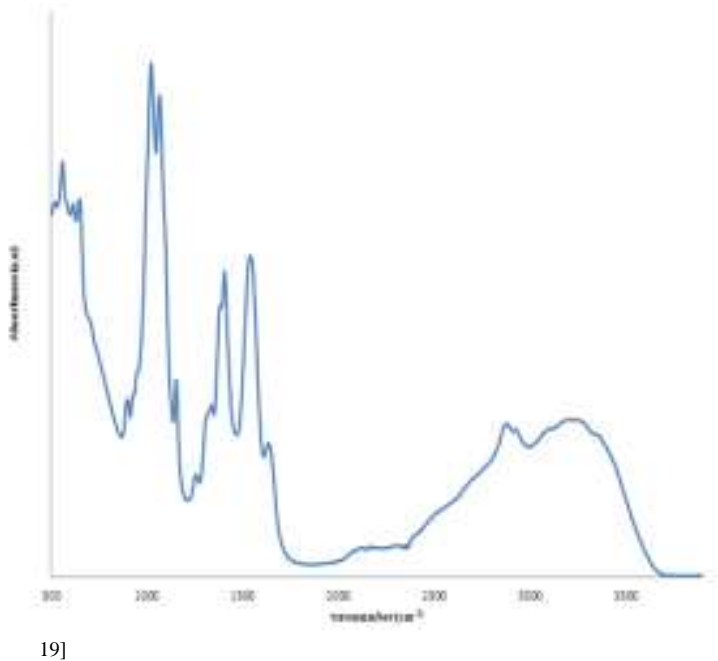

Fig. 4: IR spectrum of pure chitosan film.

Consequently the I.R. of the pure Clay is illustrated in fig (5) where the vibration bands at $3648 \mathrm{~cm}^{-1}$ is due to $\mathrm{O}-\mathrm{H}$ stretching vibration and at $3449 \mathrm{~cm}^{-1}$ referred to interlayer and interlayer $\mathrm{H}$ bonded $\mathrm{O}-\mathrm{H}$ stretching. Also the band at $1650 \mathrm{~cm}^{-1}$ is corresponding to the deformation bending vibration for $\mathrm{H}-\mathrm{OH}$.The stretching vibrational mode that observed at $1173 \mathrm{~cm}^{-1}, 1113 \mathrm{~cm}^{-1}, 1033 \mathrm{~cm}^{-1}$ are certainly different vibrational mode of $\mathrm{Si}-\mathrm{O}$ (such as stretching of quartz, longitudinal mode and normal stretching mode $)^{[20]}$.

The Al-Al-OH deformation vibrational mode is found at 928 $\mathrm{cm}^{-1}$, while for $\mathrm{Al}-\mathrm{Fe}-\mathrm{OH}$ and $\mathrm{Al}-\mathrm{Mg}-\mathrm{OH}$ deformation mode are at 886 and $849 \mathrm{~cm}^{-1}$ respectively ${ }^{[17]}$. The observed band at $797.4 \mathrm{~cm}^{-1}$ is due to $\mathrm{Si}-\mathrm{O}$ stretching vibration of quartz and silica as well as the Si-O stretching only of quartz at 774 i.e. we have diagnostic band of quartz as doublet at 797 and $774 \mathrm{~cm}^{-1}$. Also we have doublet diagnostic bands for $\mathrm{Si}-\mathrm{O}$ at 699 and at 1033 (normal stretching mode of quartz)

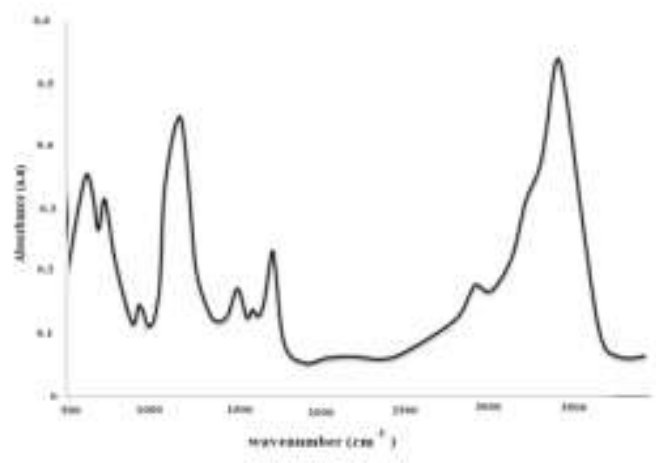

as mentioned above ${ }^{[21,22]}$.

fig. 5: I.R. spectrum of pure nanoclay (MMT).
The band at $624 \mathrm{~cm}^{-1}$ mentioned to the coupled Al-O and Si$\mathrm{O}$ vibration mode out of plane. The final bands at $525 \mathrm{~cm}^{-1}$ and $468 \mathrm{~cm}^{-1}$ that out of our scale are due to Al-O-Si and Si$\mathrm{O}-\mathrm{Si}$ deformation vibrational mode respectively ${ }^{[21]}$.

The interaction between nanoclay particles and the polymers matrix significantly depends upon the hydroxyl groups and charges present in the nanoclay layers.

Accordingly as one pay an attention to fig. (6) that indicates the I.R of the composites samples at different ratio of loading the nanoclay in the matrix of the chitosan biopolymer, one find that the $\mathrm{O}-\mathrm{H}$ stretching frequencies of the composites in range $3000 \mathrm{~cm}^{-1}$ to $3750 \mathrm{~cm}^{-1}$ were broadened and displaced to lower frequencies by about $10 \mathrm{~cm}^{-1}$ as well as the intensities of that absorption bands decrease dramatically to insure the formation of the hydrogen bonds in the all different composites.

Dissolution of Chitosan in the acetic acid resulted in reaction between an amino group of Chitosan and the acetic acid residue which lead to formation of amino acetic group (as $\mathrm{NH}_{3}^{+} \mathrm{AC}^{-}$). The addition of the nanoclay as filler to the liquid system of Chitosan/ $\mathrm{CH}_{3} \mathrm{COOH}$ facilated formation of hydrogen bonds $[13,23]$. Also one may supposed that the amino groups of chitosan were exposed on the surface of the nanocomposites material which can be observed at 1250 to $1405 \mathrm{~cm}^{-1}$ so that the soluble parts of the biopolymer chitosan containing $\mathrm{OH}$ and $\mathrm{NH}_{2}$ may form hydrogen bonds with $\mathrm{Si}-\mathrm{O}-\mathrm{Si}$ groups of the silicate layer of the nanoclay (MMT). In addition, the intensities of Al-O vibration bands at $914,839,796$ and $624 \mathrm{~cm}^{-1}$ and the structural $\mathrm{O}-\mathrm{H}$ stretching vibration are decreasing by increasing the loading filler of the nanoclay. This attributed to the relaxation of the hydrogen bonding between (Al-O)OH deformation as well as the hydrated water of exchangeable cationic metal ions on the nanoclay surface ${ }^{[24]}$.

The amide I band at $1646 \mathrm{~cm}^{-1}$ of chitosan may be overlapped with $\delta_{\mathrm{HOH}}$ bending vibration band at $1628 \mathrm{~cm}^{-1}$ of the water molecule associated to the starting clay as expected for the biopolymers with high water retention cability ${ }^{[25]}$. On the other hand the original bands of Chitosan component at $1540 \mathrm{~cm}^{-1}$ for the amide II gave a great evidence for the interaction between Chitosan and the nanoclay particles, since the $-\mathrm{NH}^{+}$group interact electro statically with negative charged sites of the clay. This frequency of the vibration mode $1540 \mathrm{~cm}^{-1}$ as in the starting chitosan corresponding to the deformation of vibration $\quad \delta_{\mathrm{NH}}$ of the protonated amino group is shifted gradually towards higher frequency values. The displacement of the vibration $\delta_{\mathrm{NH} 3}$ is depending on the loading ratio of the clay nanoparticles in the host matrix of the chitosan. At the same time one can observe a high decreasing in the intensity of this absorption band. This fact can be related to the electrostatic interaction between such groups and the negatively charged sites in the clay structure expressing the stronger interaction between cationic chitosan molecules and anionic clay surface nanoparticles ${ }^{[25]}$. Both result of X-ray diffraction and I.R. support each other indicating complexion of chitosan with nano MMT. 


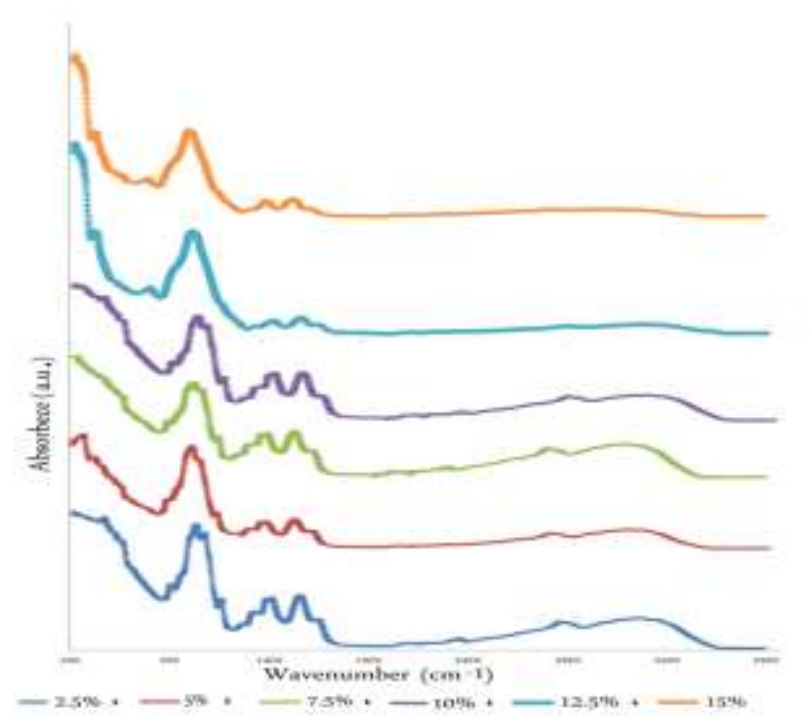

Fig. 6: IR Spectra of $(2.5,5,7.5,10,12.5$ and 15\%).

\subsection{ADSORPTION PROCESS}

Montomorillonite (MMT) nanoclay has a negative net surface charge and has little or no affinity to anionic, in there; Chitosan a nature baiopolymeric cation is an extent candidate to modify MMT for adsorption especially when we obtain composite thin film with good mechanical property.

Since the phenomenon of adsorption is largely depend on surface area and the pore structure, a composite thin film of nanoclay/chitosan is expected to achieve good condition for the adsorption of the heavy metal ions from the groundwater

Many attempts had been carried out in order to find the best film ratio of nanoclay/chitosan for enhancing the adsorption process, finally we found the composite films of highly percentage of the nanoclay such as 70:30, 75:25 and 80:20 were better than the less other selective ratios.

The percentage of the nanoclay more than $80 \%$ were brittle not a suitable to achieve good adsorption.

We choice the composite $75: 25$ because it was the optimum composite ratio achieving the highest adsorption of heavy metal ions as Manganese at the different conditions of adsorption such as $\mathrm{pH}$, contact time, temperature and initial concentration.

\subsection{ADSORPTION CALCULATION}

The amount of adsorption $\mathrm{q}_{\mathrm{e}}(\mathrm{mg} / \mathrm{g})$ and the percentage of removal were calculated by the following equations ${ }^{[26]}$ :

$$
\mathrm{q}_{\mathrm{e}}=\frac{\mathrm{V}\left(\mathrm{C}_{\mathrm{o}_{\mathrm{o}}}-\mathrm{C}_{\mathrm{e}}\right)}{\mathrm{m}}
$$

$$
\text { Adsorption }(\%) \frac{\left(C_{o^{-}}-C_{e}\right)}{C_{o}} \times 100
$$

Where $\mathrm{C}_{0}$ and $\mathrm{C}_{\mathrm{e}}$ are the initial $\mathrm{Mn}$ (II) concentration and the concentration at equilibrium in $\mathrm{mg} / \mathrm{l}, \mathrm{m}$ is the mass of the adsorbent and $\mathrm{V}$ is the volume of solution.

Two adsorption isotherms models have been used to analyze the adsorption data equilibrium models to fit the experimental data by two equations ${ }^{[27]}$ :

(i) Langmuir

$$
\frac{C_{e}}{q_{e}}=\frac{1}{K_{L} b}+\frac{C_{e}}{b}
$$

Where $\mathrm{q}_{\mathrm{e}}(\mathrm{mg} / \mathrm{g})$ is the equilibrium adsorption capacity and $\mathrm{C}_{\mathrm{e}}(\mathrm{mg} / \mathrm{l})$ is the equilibrium concentration. While, $\mathrm{K}_{\mathrm{L}}(\mathrm{l} / \mathrm{mg})$ and $b(\mathrm{mg} / \mathrm{g})$ are the Langmuir constants related to the sorption capacity and the adsorption energy, respectively.

(ii) Freundlich

$$
\log q_{e}=\log K_{f}+\frac{1}{n} \log C_{e}
$$

While, $\mathrm{K}_{\mathrm{F}}(\mathrm{L} / \mathrm{mg})$ is the Freundlich constant and $1 / \mathrm{n}$ is the heterogeneity factor.

Adsorption kinetics is used to explain the adsorption mechanism and adsorption characteristics. The pseudo-firstorder and second-order kinetics equations ${ }^{[28,29]}$ in linear forms are expressed as:

$$
\begin{aligned}
& \log \left(q_{e}-q_{t}\right)=\log \left(q_{e}\right)-\left(\frac{k_{1}}{2.303}\right) t \\
& \frac{\mathrm{t}}{\mathrm{q}_{\mathrm{t}}}=\frac{1}{\left(\mathrm{k}_{2} \mathrm{q}_{\mathrm{e}}^{2}\right)}+\left(\frac{1}{\mathrm{q}_{\mathrm{e}}}\right) \mathrm{t}
\end{aligned}
$$

Where $\mathrm{q}_{\mathrm{t}}$ and $\mathrm{q}_{\mathrm{e}}$ are the amounts of nano-composite material adsorbed at time $t$ and at equilibrium, respectively; $\mathrm{k}_{1}$ and $\mathrm{k}_{2}$ are the pseudo-first-order and second-order rate constants for the adsorption process.

The thermodynamic parameters provide in-depth information on inherent energetic changes including Gibbs free energy change $\left(\Delta \mathrm{G}^{\circ}\right)$, enthalpy change $\left(\Delta \mathrm{H}^{\circ}\right)$, and entropy change $\left(\Delta \mathrm{S}^{\circ}\right)$ for the adsorption process which are obtained by the following equations ${ }^{[30,31]}$ :

$$
\begin{aligned}
& \Delta G^{o}=-R T \ln b \\
& \ln b=\frac{\Delta S^{o}}{R}-\frac{\Delta H^{o}}{R T}
\end{aligned}
$$

Where $\mathrm{R}$ is the ideal gas constant $\left(\mathrm{kJ} \mathrm{mol}^{-1} \mathrm{~K}^{-1}\right)$, $\mathrm{T}$ is the temperature $(\mathrm{K})$, and $\mathrm{b}$ is a Langmuir constant related to the adsorption energy (from the Langmuir isotherm).

\subsubsection{Effect of starting solution $\mathrm{pH}$ on the removal of $\mathrm{Mn}$ (II)}

The effect of starting solution $\mathrm{pH}$ on the removal $\%$ of $\mathrm{Mn}$ (II) from solutions with an initial concentrations of 80 $\mathrm{mg} / \mathrm{L}$, on $0.25 \mathrm{~g} / \mathrm{L}$ of adsorbent after 105 minutes is shown in Fig.(7). The data indicate that the amounts of $\mathrm{Mn}$ (II) adsorbed on the prepared clay/chitosan composite material decrease with decreasing $\mathrm{pH}$ for a starting solution $\mathrm{pH} \leq 5$. These phenomenon can be explain by the presence of $\mathrm{H}+$ ions in to the solution were competing with the $\mathrm{Mn}$ (II) ions for active binding sites on the surface of the composite . 
Fewer binding sites were available for $\mathrm{Mn}$ (II) cation to be adsorbed, in addition the most amine groups in chitosan become protonated $\mathrm{NH}^{+3}$ at lower $\mathrm{pH}$ which reduce the available binding sites for $\mathrm{Mn}(\mathrm{II})$ ions.

As Mn(II) transported from the solution to the adsorbent the protonated amino groups inhibit the approach of $\mathrm{Mn}$ (II) due to the electrostatic repulsion force exerted by $\mathrm{NH}^{+3}$ on the adsorbent surface ${ }^{[32]}$.

When $\mathrm{pH}$ increase to 5.5 the amino groups become deprotonated hence it is free to interact and bind with $\mathrm{Mn}(\mathrm{II})$ ions, however, $\mathrm{pH}$ range of 5 to 6 was optimum for $\mathrm{Mn}$ (II) to be adsorbed by the nanoclay/chitosan composite film 75:25, at $\mathrm{pH}$ higher than 6 the cumulative effect of adsorption and perception of the ions may be occurred.

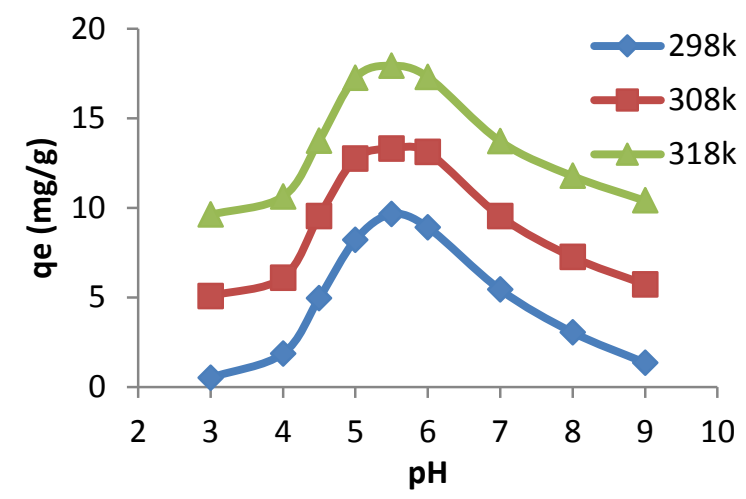

Fig.7: Effect of $\mathrm{pH}$ values on the adsorption capacity of $\mathrm{Mn}$ (II) at different temperatures onto Chitosan/Clay ratio 25:75 (initial concentration of $80 \mathrm{mg} / \mathrm{L}$, adsorbent dosage of 0.25 $\mathrm{g} / \mathrm{L}$, stirring rate of $160 \mathrm{rpm}$, contact time of $105 \mathrm{~min}$ ).

\subsubsection{ADSORBENT MASS}

Different amounts of Chitosan/Clay composite materials $(0.10,0.15,0.20,0.25,0.30,0.35$ and $0.40 \mathrm{~g} / \mathrm{L})$ were added to a series of $100 \mathrm{~mL}$ of manganese solutions with initial concentration of $80 \mathrm{mg} / \mathrm{L}$ at $\mathrm{pH} 5.5$ and stirring rate of 160 rpm for contact time $105 \mathrm{~min}$ to reach the equilibrium. Then the aqueous samples were filtered, and the residual $\mathrm{Mn}$ (II) concentrations were analyzed by Spectrophotometer. The effect of the adsorbent mass on the Mn(II) adsorption in 80 $\mathrm{mg} / \mathrm{L}$ solutions is shown in Fig.(8)

At all temperatures, the first removal percentage of $\mathrm{Mn}$ (II) decreased with increasing the composite dosage up to dose above $0.2 \mathrm{~g} / \mathrm{L}$ [33].

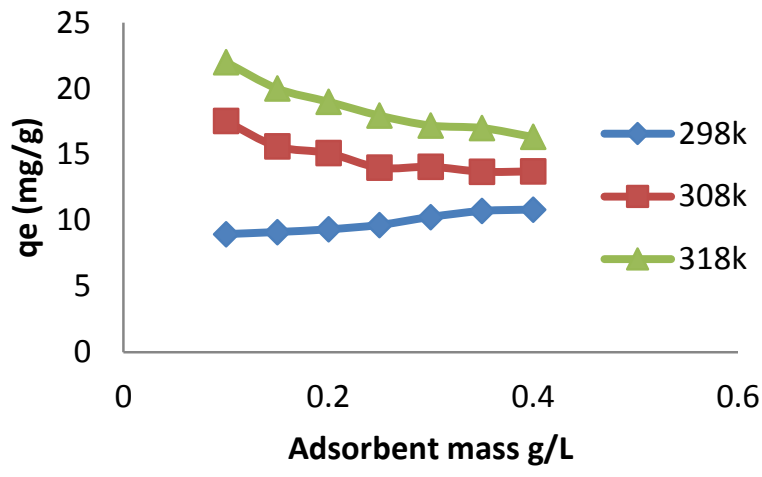

Fig. 8: Effect of adsorbent mass on the adsorption capacity of $\mathrm{Mn}$ (II) at different temperatures onto Chitosan/Clay ratio of 25:75 (initial concentration of $80 \mathrm{mg} / \mathrm{L}, \mathrm{pH}$ value of 5.5, stirring rate of $160 \mathrm{rpm}$, contact time of $105 \mathrm{~min}$ ).

\subsubsection{Initial Mn(II) concentration and adsorption isotherm}

The effect of different $\mathrm{Mn}$ (II) concentrations determined after experimental studies were carried out for a range of metal concentrations $(20-80 \mathrm{mg} / \mathrm{L})$. A definite dosage of Clay/Chitosan composite materials $(0.25 \mathrm{~g} / \mathrm{L})$ was added to a series of $100 \mathrm{~mL}$ of $\mathrm{Mn}(\mathrm{II})$ solutions with the different initial concentrations of $20,30,40,50,60,70$ and $80 \mathrm{mg} / \mathrm{L}$ at $\mathrm{pH}$ 5.5 , and stirring rate at $160 \mathrm{rpm}$ for contact time $105 \mathrm{~min}$ to reach the equilibrium. The removal of $\mathrm{Mn}(\mathrm{II})$ shown in Fig.(9) indicates that all ratios of Clay/Chitosan composite materials apparently remove a considerable amount of $\mathrm{Mn}$ (II) from the aqueous solutions. The adsorption efficiency for the composite ratio increases to a certain level $(40 \mathrm{mg} / \mathrm{L})$, and saturates beyond a certain concentration. Saturation resulted when no more metal ions could be adsorbed on the surface of the composites where the adsorption occurred. The removal with initial $\mathrm{Mn}$ (II) concentrations exhibit that the removal amounts are linearly proportional to the initial metal concentrations. However, the complete removal of $\mathrm{Mn}$ (II) was observed at initial concentration $20 \mathrm{mg} / \mathrm{L}$ at $308 \mathrm{k}$ and at initial concentrations 20 and $30 \mathrm{mg} / \mathrm{L}$ at $318 \mathrm{k}$.

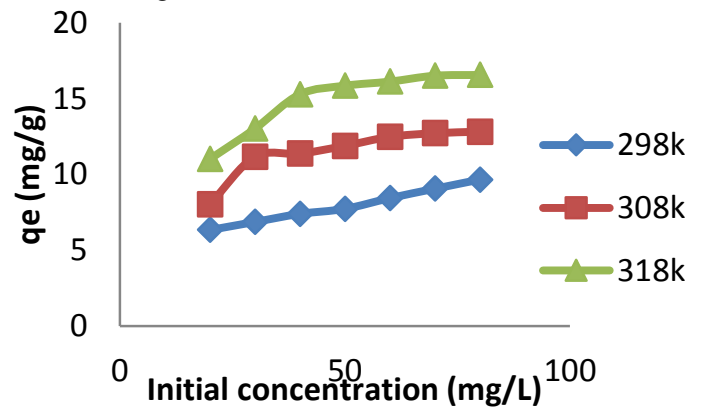

Fig. 9: Effect of initial $\mathrm{Mn}(\mathrm{II})$ concentration on the adsorption capacity at different temperatures onto Chitosan/Clay ratio of 5:75 (adsorbent dosage of $0.25 \mathrm{~g} / \mathrm{L}$, $\mathrm{pH}$ value of 5.5, stirring rate of $160 \mathrm{rpm}$, contact time of 105 $\min )$. 
For better understanding of the mechanism of manganese adsorption was illustrated by adsorption kinetics. When the pseudo-second-order model considers the rate-limiting step as the formation chemisorptive bond involving sharing or exchange of electrons between adsorbate and the adsorbent ${ }^{[34]}$, the above results obtained consistently suggests that the rate-determining step may be chemical adsorption and the adsorption behavior may involve the valence forces through sharing electrons between the $\mathrm{Mn}(\mathrm{II})$ ions and adsorbents $[35,36]$.

\subsubsection{Contact time and adsorption kinetics}

Fig.(10) shows the effect of contact time on the adsorption capacity of initial $\mathrm{Mn}(\mathrm{II})$ concentration $(80 \mathrm{mg} / \mathrm{L}$ ) onto Clay/Chitosan composite materials of ratio 75:25 (0.25 g/L) at $\mathrm{pH} 5.5$, stirring rate of $160 \mathrm{rpm}$ and different temperatures, 298, 308 and $318 \mathrm{k}^{\circ}$. The fast $\mathrm{Mn}$ (II) removal rate in the beginning (within the first 60 minutes) is attributed to the rapid diffusion of $\mathrm{Mn}$ (II) from the solution to the external surfaces of adsorbent. The subsequent slow adsorption process is attributed to the longer diffusion range of $\mathrm{Mn}$ (II) into the inner-layers of Clay/Chitosan composite materials. Such slow diffusion will lead to a slow increase in the adsorption curve at later stages.

From Fig. (10), the adsorption rate increased with increasing the temperature and the concentration gradients becomes reduced as the time proceeds, owing to the accumulation of more than $12.5 \mathrm{mg}$ of $\mathrm{Mn}$ (II) adsorbed per gram of Clay/Chitosan composite surface sites of ratio 75:25 after 60 min at temperature $318 \mathrm{k}$, leading to the maximum adsorption capacity $17.92 \mathrm{mg} / \mathrm{g}$ after $105 \mathrm{~min}$.

The increase in the amount of $\mathrm{Mn}(\mathrm{II})$ adsorbed at equilibrium with increasing the temperature may be due to the acceleration of some original slow adsorption steps or the creation of some active sites on the adsorbent surface. Increasing the temperature my also produce a swelling effect within the internal structure of the clay/chitosan composite, enabling a large number of $\mathrm{Mn}$ (II) ions to penetrate in to the pores. The adsorption process may involve chemical bonds and ion exchange since the temperature is the main parameter effecting the above two process ${ }^{[37]}$.

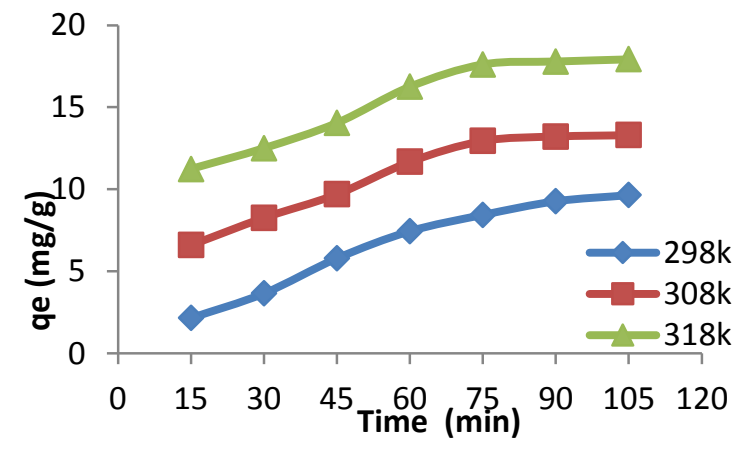

Fig. 10: Effect of contact time on the adsorption capacity of $\mathrm{Mn}$ (II) at different temperatures onto Chitosan/Clay ratio of 25:75 (initial concentration $80 \mathrm{mg} / 1$, pH 5.5, adsorbent mass $0.25 \mathrm{~g} / \mathrm{l}$, stirring rate $160 \mathrm{rpm})$.

\subsection{Kinetic Isotherm}

\subsubsection{Pseudo-first and pseudo-second- order}

To evaluate the adsorption kinetics of $\mathrm{Mn}$ (II) ions on Clay/Chitosan composite, the pseudo-first-order and pseudo-second-order models (Equations 5 and 6) were applied to analyze the experimental data. The kinetic parameters were obtained from fitting results and presented in Table (1). From the fit curve shown in Figs $(11,12)$ and the relative coefficient, it can be seen that the pseudosecond-order model fit the adsorption of $\mathrm{Mn}$ (II) onto Clay/Chitosan composite better than the pseudo-first-order model.

In this study, as illustrated in Figs $(11,12)$, the slopes and intercepts of the plot of $t$ versus $\log \left(q_{e}-q_{t}\right)$ and $t / q_{t}$ were used to determine the rate constants $k_{1}$ and $k_{2}$ and the equilibrium adsorption density $\mathrm{q}_{\mathrm{e}}$ of the pseudo-first-order and pseudo-second-order, respectively, Table (1). The correlation coefficient for the pseudo-first-order model of Clay/Chitosan ratio of 75:25 $\left(\mathrm{R}^{2}=0.942\right)$ was lower than that of the pseudo-second-order $\left(\mathrm{R}^{2}=0.990\right)$ at $318 \mathrm{k}^{\mathrm{O}}$, respectively. This suggests that the pseudo-first-order equation may not be sufficient to depict the kinetics of $\mathrm{Mn}$ (II) onto the Clay/Chitosan composites hence it appear that, the system under consideration is more appropriately described by pseudo-second-order mode which based on the assumption that the rate limiting step may be chemical sorption involving valancy forces through sharing or exchange of electrons between sorbent and sorbate ${ }^{[38]}$.

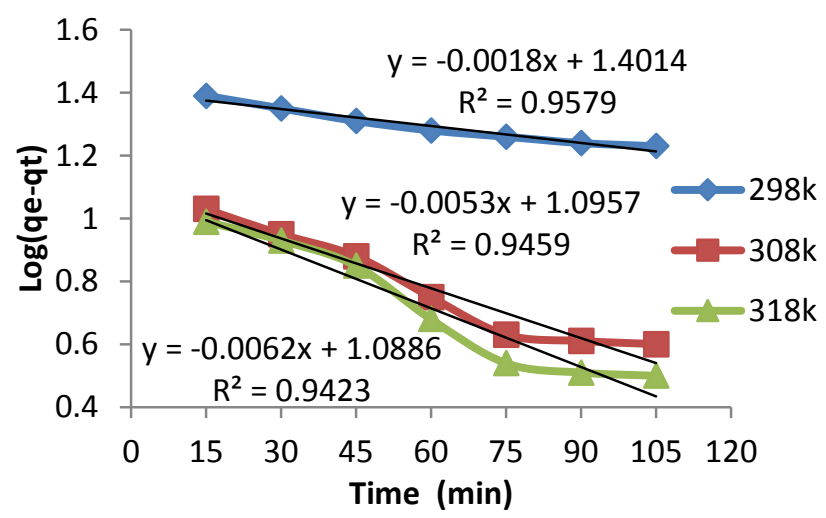

Fig. 11: Adsorption kinetics of the pseudo-first-order model for the $\mathrm{Mn}$ (II) adsorption of Chitosan/Clay ratio of 25:75 at different temperatures (adsorbent dosage of $0.25 \mathrm{~g} / \mathrm{L}, \mathrm{pH}$ value of 5.5 , stirring rate of $160 \mathrm{rpm}$, contact time of 105min). 


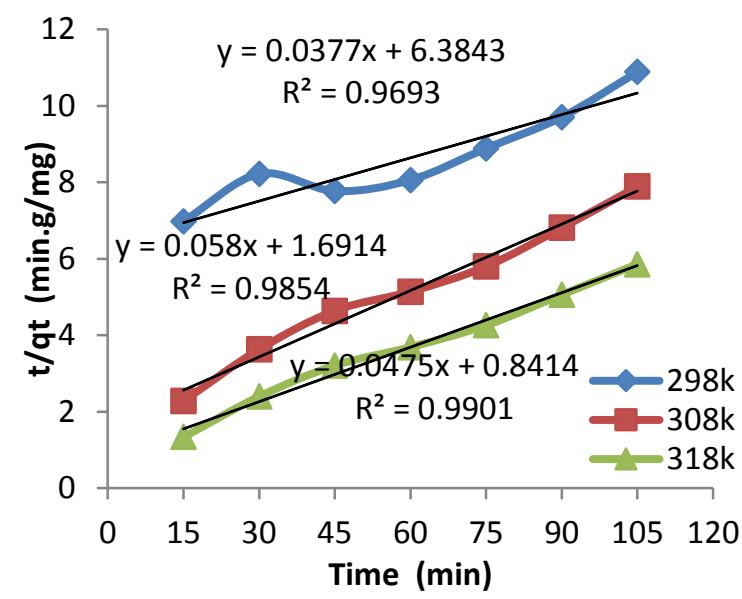

Fig.12: Adsorption kinetics of the pseudo-second-order model for the $\mathrm{Mn}$ (II) adsorption of Chitosan/Clay ratio of 25:75 at different temperatures (adsorbent dosage of $0.25 \mathrm{~g} / \mathrm{L}, \mathrm{pH}$ value of 5.5 , stirring rate of $160 \mathrm{rpm}$, contact time of $105 \mathrm{~min}$ ).

Table (1): Kinetic parameters of the pseudo-first- and pseudo-second-order models for the $\mathrm{Mn}$ (II) adsorption at different temperatures onto Clay/Chitosan ratio of 75:25 (initial $\mathrm{Mn}(\mathrm{II})$ concentration $80 \mathrm{mg} / \mathrm{l}$, pH 5.5, adsorbent mass $0.25 \mathrm{~g} / \mathrm{l}$, stirring rate $160 \mathrm{rpm})$.

\begin{tabular}{|c|c|c|c|}
\hline \multicolumn{4}{|c|}{ Pseudo-first-order model } \\
\hline $\mathbf{T}(\mathbf{k})$ & $K_{1} \quad\left(\min ^{-1}\right)$ & qe $\quad(\mathrm{mg} / \mathrm{g})$ & $\mathbf{R}^{2}$ \\
\hline 298 & $4.15 \times 10^{-3}$ & 25.2 & 0.958 \\
\hline 308 & 0.012 & 12.47 & 0.946 \\
\hline 318 & 0.014 & 12.26 & 0.942 \\
\hline \multicolumn{4}{|c|}{ Pseudo-second-order model } \\
\hline $\mathbf{T}(\mathbf{k})$ & $\begin{array}{c}\mathbf{K}_{2} \\
\left(g^{-}-g^{-1} \mathbf{L m i n}^{-1}\right)\end{array}$ & qe $(\mathrm{mg} / \mathrm{g})$ & $\mathbf{R}^{2}$ \\
\hline 298 & $2.23 \times 10^{-3}$ & 26.53 & 0.969 \\
\hline 308 & $1.99 \times 10^{-3}$ & 17.24 & 0.985 \\
\hline 318 & $2.68 \times 10^{-3}$ & 21.05 & 0.990 \\
\hline
\end{tabular}

\subsubsection{Langmaur and Freudlich isotherm}

Adsorption isotherm models are usually used to describe the interaction between the adsorbent and the adsorbate at equilibrium state, The equilibrium data were analyzed using the Langmuir and Freundlich equilibrium models in order to obtain the best fitting isotherm (Equations 3 and 4).
According to Fig.(13), $\mathrm{K}_{\mathrm{F}}$ and $\mathrm{n}$ are the Freundlich constants, which represent sorption capacity and sorption intensity, respectively and they can be evaluated from the intercept and slope of the linear plot of $\log$ qe versus $\log \mathrm{Ce}$ and given in Table(2). While, from Fig.(14), a line was obtained as the values of $b$ and $k_{L}$ can also be obtained by the slope and intercept of the line and given in Table(2).

The isotherm models of $\mathrm{Mn}$ (II) removal were studied by different initial concentrations ranging from 20 to $80 \mathrm{mg} / \mathrm{L}$ at different temperatures, 298,308 and $318 \mathrm{k}^{\mathrm{O}}$, a pH of 5.5 , adsorbent mass of $0.25 \mathrm{~g}$ and after $105 \mathrm{~min}$. Table(2) summarizes the Langmuir and Freundlich constants and the calculated coefficients. The results show that the linear correlation coefficients for Langmuir models at higher temperature $\left(318 \mathrm{k}^{\mathrm{O}}\right)$ onto Clay/Chitosan composite materials of ratio75:25was 0.994 , while the correlation coefficients for Freundlich models was 0.778 . The higher regression coefficient $\mathrm{R}^{2}$ for Langmuir model indicated that the Langmuir model fits the experimental data better than the Freundlich one. Moreover, the Langmuir constant b value, which is a measure of the monolayer adsorption capacity of the adsorbent, and the Langmuir constant, $\mathrm{k}_{\mathrm{L}}$, which denotes adsorption energy, were found to be $17.83 \mathrm{mg} / \mathrm{g}$ and $0.9 \mathrm{~L} / \mathrm{mg}$ respectively at temperature $318 \mathrm{k}^{\circ}$ which are greater than the other value at temperature 298 or $308 \mathrm{k}^{\circ}$.

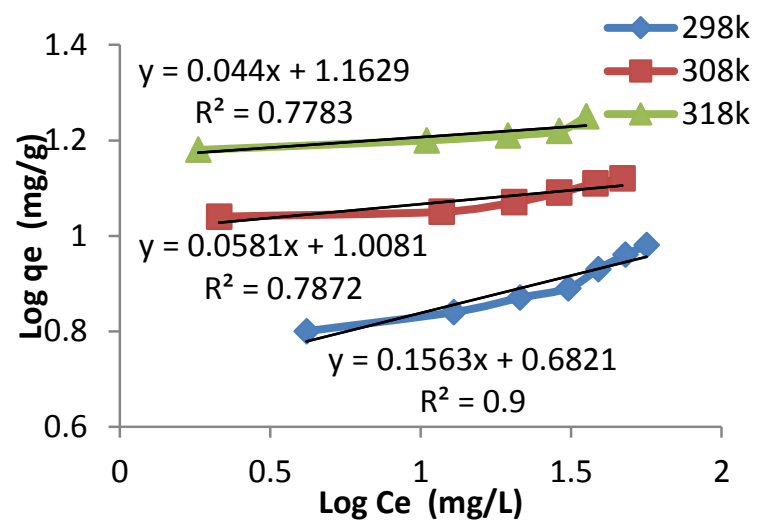

Fig. 13: Freundlich adsorption isotherm models for the removal of $\mathrm{Mn}(\mathrm{II})$ at different temperatures onto Chitosan/Clay ratio of 25:75 (adsorbent dosage of $0.25 \mathrm{~g} / \mathrm{L}$, $\mathrm{pH}$ value of 5.5, stirring rate of 160rpm, contact time of 105 min). 


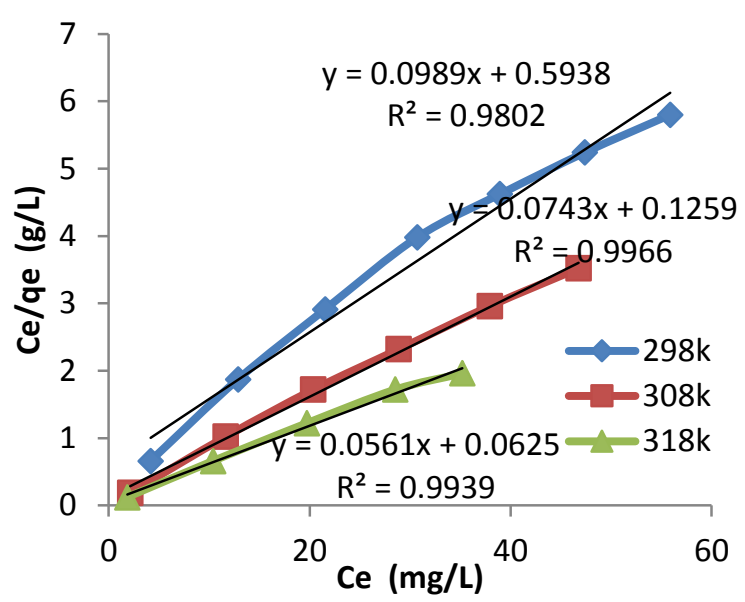

Fig. 14: Langmuir adsorption isotherm models for the removal of $\mathrm{Mn}$ (II) at different temperatures onto Chitosan/Clay ratio of 25:75 (adsorbent dosage of $0.25 \mathrm{~g} / \mathrm{L}$, $\mathrm{pH}$ value of 5.5, stirring rate of $160 \mathrm{rpm}$, contact time of 105 $\min )$.

Table (2): Isotherm parameters for $\mathrm{Mn}$ (II) removal at different temperatures onto Clay/Chitosan ratios of 75:25 (adsorbent dosage of $0.25 \mathrm{~g} / \mathrm{L}, \mathrm{pH}$ value of 5.5 , stirring rate of $160 \mathrm{rpm}$, contact time of $105 \mathrm{~min}$ ).

\begin{tabular}{|c|c|c|c|}
\hline \multicolumn{4}{|c|}{ Langmuir isotherm model } \\
\hline T (k) & KL $_{\mathbf{L}}$ (L/mg) & b (mg/g) & $\mathbf{R}^{\mathbf{2}}$ \\
\hline 298 & 0.67 & 10.11 & 0.98 \\
\hline 308 & 0.59 & 13.46 & 0.997 \\
\hline 318 & 0.9 & 17.83 & 0.994 \\
\hline \multicolumn{2}{|c|}{ Freundlich isotherm model } \\
\hline 298 & 4.81 & $\mathbf{n}$ & $\mathbf{R}^{\mathbf{2}}$ \\
\hline 308 & 10.19 & 17.21 & 0.787 \\
\hline 318 & 14.55 & 22.73 & 0.778 \\
\hline
\end{tabular}

\subsubsection{Temperature and thermodynamics}

All experiments in this study were carried out at different temperatures 298,308 , and $318 \mathrm{k}^{\circ}$. The thermodynamic parameters were calculated and the nature of the adsorption processes was determined at different temperatures and the adsorption capacity of $\mathrm{Mn}$ (II) for Clay/Chitosan composite increased with increasing the temperature.
From equation 7 and Table (3), the negative values for the Gibbs free energy $\left(\Delta \mathrm{G}^{\circ}\right)$ at higher temperature for Clay/Chitosan ratio of 75:25 were $-7.60 \mathrm{kJmol}^{-1}$. Showing that the adsorption process is'

spontaneous and the degree of spontaneity of the reaction increased with the increase in the temperature and the value of $\Delta \mathrm{G}^{\circ}$ becomes more negative indicating that higher temperature facilitates the adsorption of $\mathrm{Mn}$ (II) on Chitosan/Clay composite due to a greater driving force of adsorption $^{[39]}$.

Equation 8 represents the enthalpy $\left(\Delta \mathrm{H}^{\circ}\right)$ and the entropy $\left(\Delta \mathrm{S}^{\circ}\right)$ changes that were calculated from a plot of $\ln b$ (from the Langmuir isotherm) vs. 1/T, Fig.(15). The results of these thermodynamic calculations are shown in Table (3). The positive value of $\Delta \mathrm{H}^{\circ}$ suggests that the interaction of $\mathrm{Mn}(\mathrm{II})$ adsorbed by Clay/Chitosan composite is endothermic process. Table (3), also shows that the $\Delta \mathrm{S}^{\circ}$ value was positive which revealed the increased randomness at the solid-solution interface during the process of adsorption ${ }^{[39}$, 40].

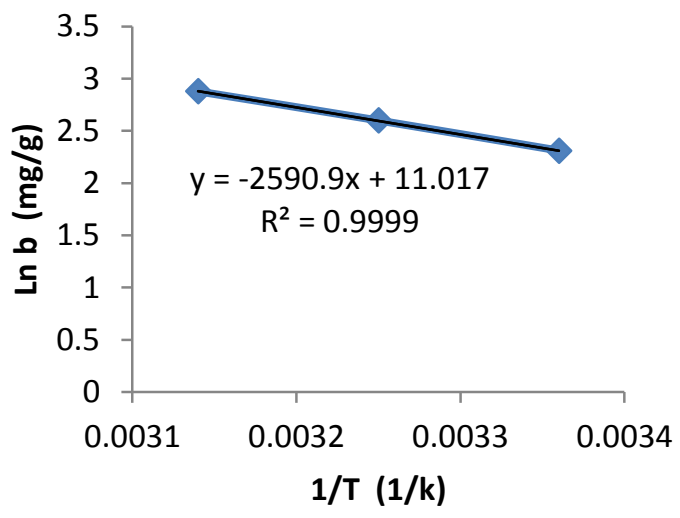

Fig.(12): Plot of the Langmuir isotherm constant (ln b) vs. temperature $(1 / \mathrm{T})$ of Clay/Chitosan ratio of 75:25 (The thermodynamic parameters in Table 3 are determined from this graph).

Table3: Thermodynamic constants for the $\mathrm{Mn}(\mathrm{II})$ adsorption onto Clay/Chitosan ratio of $75: 25$ at different temperatures (initial $\mathrm{Mn}$ (II) concentration $80 \mathrm{mg} / \mathrm{l}$, pH 5.5, adsorbent mass $0.25 \mathrm{~g} / \mathrm{l}$, stirring rate $160 \mathrm{rpm}$ ).

\begin{tabular}{|c|c|c|c|c|c|}
\hline $\mathbf{T}(\mathbf{k})$ & Lnb & $\begin{array}{c}\Delta G^{o} \\
\left(\mathrm{kJmol}^{-1}\right)\end{array}$ & $\begin{array}{c}\Delta H^{o} \\
\left(\mathrm{kJmol}^{-1}\right)\end{array}$ & $\begin{array}{c}\Delta S^{o} \\
\left(\mathrm{kJmol}^{-1} \mathbf{K}^{-1}\right)\end{array}$ & $\mathbf{R}^{2}$ \\
\hline 298 & 2.31 & -5.71 & \multirow{3}{*}{21.5} & \multirow{3}{*}{0.091} & \multirow{3}{*}{0.999} \\
\hline 308 & 2.60 & -6.65 & & & \\
\hline 318 & 2.88 & -7.60 & & & \\
\hline
\end{tabular}


International Journal of Science and Engineering Applications

Volume 4 Issue 4, 2015, ISSN-2319-7560 (Online)

\section{CONCLUSION}

Preparation and characterization of nano MMT/Chitosan with different percentage loading of the nanoparticles were examined using XRD and I.R. The XRD confirm the existence and the interaction of the nanoclay within chitosan confirming the structural changes occurred in the different composites. The I.R. gave an evidence for the structural changes due to the interaction through $\mathrm{OH}$ and amino groups.

The adsorption process by nanoclay/chitosan composite is enhanced at certain condition as the weight ratio of the composite $75 / 25, \mathrm{pH}=5.5$, the adsorbent mass about 0.25 $\mathrm{g} / \mathrm{L}$, the $\mathrm{Mn}(\mathrm{II})$ concentration $80 \mathrm{~g} / \mathrm{L}$ and equilibrium contact time $105 \mathrm{~min}$.

The kinetic isotherm referred to the pseudo-second-order model

The adsorption isotherm followed Langmuir model.

The calculated thermodynamics data indicated that the adsorption process is spontaneous and endothermic.

Accordingly the prepared composite system of material are very promising of removing $\mathrm{Mn}(\mathrm{II})$ from aqueous solution .

The adsorption is available tool for controlling the level of $\mathrm{Mn}$ (II) pollution. The utilizing of low cost adsorbents for treatment of groundwater containing metal ions is helpful as simple, effective and economical.

\section{REFERENCES}

[1] Pandey, S. Mishra, Journal of colloid Interface Scince,2011, Vol. 361, p.p.: 509-520.

[2] Han Y.; Lee, S.; Choi, K.H., Y Yournal of Physics and Chemistry of Solids, 2010, Vol. 71, p.p.: 464-467.

[3] Chang, M.Y.; R.S.; Journal of Colloid and Interface Scince, 2004, Vol. 278, p.p.: 18-25.

[4] Krajewska, B.; Enzyme and Microbial Technology, 2004, Vol.35, p.p.: 126-134.

[5] Lavorgna, M.; Piscitelli, F.; Mangiacapra, P.; Buonocore, G.; Carbohydrate Polymers, 2010, Vol.82, p.p.: 291298.

[6] Chivrac, F.; Pollet, E.; Averous, L.; Material Scince and Engineering, 2009, Vol.67, p.p.: 1-17.2004

[7] Utracki, L.A.; Clay-containing Polymeric Nanocomposites, p.p:73-96, Rapra Technology Limited, England.

[8] Samuels R. J.; J. Polym. Sci. Phys. Ed.; 1981, 19:1081.

[9] Ogawa, K.; Yui, T.; Miya and M.; Bioscince Biotechnology and Biochemistry,1992, Vol. 56, p.p.: 858-862.

[10] Bhattacharya S. S. and Mandot Adhar, 2014, Research Journal of Engineering Scinces, Vol. 3(3), p.p.: 10-16.
[11] M. A. Khedr, A. I. Waly, A. I. Hafez and Hanaa Ali, 2012, Aust. J. Basic and Appl. Sci.; Vol. 6(6), p.p: 216226.

[12] Ray S. S. and Okamoto M.; Prog. Polym. Sci.; 2003, Vol.28, p.p.: 1539-1641.

[13] S. F. Wang, L. Shen, Y. J. Tong, L. Chen, I.Y. Phang, P.Q. Lim, T.X. Liu, Polymer Degradation and Stability,2005, Vol. 90, p.p.: 123-131.

[14] Mano, J. F.; Koniarova D.; Reis R. L.; 2003, Journal of Materials Scince, Vol. 14, p.p: 127-135.

[15] Vhen Z.; Xiumei Mo, Oing F.; Materials Letters,2007, Vol. 61, p.p: 3490-3494.

[16] Xu X.; Ding Y.; Qian Z.; Wang F.; Wen B.; Zhou H.; Zhang S.; Yang M.;2009, Polymer Degradation and Stability, Vol. 94, p.p.: 113-123.

[17] Darder M.; Colilla M.; Ruiz-Hitzky E.; Chemical Material, 2003, Vol. 15, p.p.: 3774-3780.

[18] Paluszkiewicz C.; Stodolak E.; Hasik M. and Blazewicz M.; Specrochim Acta part A, 2011, Vol.79, p.p.: 784788.

[19] Yuan Q.; Shah J.; Hein S.; Misra R. D. K.; Acta Biomaterial,2010, Vol. 20, p.p.: 1140-1148.

[20] Madejova J.; Vibrational Spectroscopy,2003, Vol. 31, p.p.:1-10.

[21] Z. Navratilova, P. Wojtowicz, L. Vaculikova and V. Sugarkova, Acta Geodym. Geomater,2007, Vol.4, No. 3 (147), p.p.: 59-69.

[22] X. Wang, Y. Du, J. Yang, X. Wang, X. Shi and Y. Hu, Polymer, 2006, Vol. 47, No.19, p.p.: 6738-6744.

[23] E. Günister, D. Pestreli, C. H. Vnlü, O. Atici and N. Güngö, Carbohydrate Polym.; 2007, Vol.67, p.p.: 358365.

[24] Y. Han, S. H. Lee, K. H. Choi, In Pac J. Phys. And Chemis. Of Solid,2010, p.p.: 464-467.

[25] M. S. Mostafa, A. A. Baker, Gh. Eshaq, M. M. Kamel, Desalination and Water Treatment, DOI: 10.1080/19443994.2014.934725, p.p.:1-9.

[26] AL-Sayed A. Bakr, Yasser M. Moustafa, Mostafa M. Khalil, Mohamed M. Yehia and Eman A. Motawea, 2015, Vol. 93 (3), p.p.: 289-296.

[27] A.A. Bakr, M.S. Mostafa, Gh. Eshaq and M. M. Kamel, Desalination and Water Treatment, DOI:10.1080/19443994.2014.934729, p.p: 1-8.

[28] A. A. Bakr, Gh. Eshaq, A. M. Rabie, A. H. Mody, A. E. Elmetwally, Desalination and Water Treatment, DOI: 10.1080/19443994.2015.1051126, p.p.: 1-12.

[29] AL-Sayed A. Bakr, Yasser M. Moustafa, Mostafa M. Khalil, Mohamed M. Yehia and Eman A. Motawea, Journal of Enviroment Chemical Engineering, 2015, Vol. 3 (3), p.p.: 1486-1496. 
[30] Yu L. and Ya-Juan L.; Sep. Purif. Technol.; 2008, DOI: 10.1016/j.seppur.2007.10.002, p.p.: 229-242.

[31] Pham Xuan Nui, Petro. VIETNAM Journal,2014, Vol.6, p.p.: 62-68

[32] D. P. Das, J. Das, K. Parida, J. Colloid Interface Sci.; DOI: 10.1016/ S0021-9797(03)00082-1, P.P: 213-220.

[33] C. Chen, J. L. Wang, J. Hazard. Mater.; DOI: 10.1016/j.jhazmat.2007.05.046, p.p.:65-70.

[34] A. K. Bhattacharya, T. K. Naiya, S. N. Mondal, S. K. Das, Chem. Eng. J.; DOI:10.1016/J.CEJ.2007.05.021, P.P.: 529-541.

[35] L. M. Zhou, J. Y. Jin, Z. R. Liu, X. Z, Liang, C. Shang, J. Hazard. Mater.; DOI:10.1016/j.hazmat.2010.10.012, p.p.: 1045-1052.

[36] N. Zahra Pak, J. Anal. Environ. Chem.; 2012,Vol.13, No.1.

[37] L. Ai, C. Zhang, Z. Chen, J. Hazard. Mater.; DOI:10.1016/j.j Hazmat.2011.06.068.; p.p.: 15151524.

[38] Ho Y. S. and McKay G.; Process Biochem.; 1999a, Vol.34(5), p.p.: 451-465.

[39] K. H. Gho, T. T. Lim, Z. Dong, Environ. Sci. Technol.;2009, DOI:10.1021/es 802811n.; p.p.: 2537 2543.

[40] M. Dakiky, M. Khamis, A. Manassra, Adv. Environ.;2002,DOI:10.1016/S1093-0191(01)00079X.; p.p: $533-540$. 